\title{
Calibration of erodibility testing devices for bridge design support
}

\author{
H. Shan, O. Wiblishauser, C. Lin \& J. Shen \\ Genex Systems, 6300 Georgetown Pike, McLean, VA 22101, USA \\ K. Kerenyi \\ Federal Highway Administration, Department of Transportation, \\ 6300 Georgetown Pike McLean, VA 22101, USA
}

\begin{abstract}
In order to promote bridge safety under flood conditions, the U. S. Federal Highway Administration (FHWA) has been developing more reliable bridge scour evaluation methods that take into account bridge site specific flow conditions and stream bed material properties. The FHWA is currently developing two such devices: the Ex-situ Scour Testing Device (ESTD) and the laboratory version of an In-situ Scour Testing Device (Lab-ISTD), both test erodibility of stream bed material under specific flow conditions. To maintain portability and robustness, the Lab-ISTD has evolved into a compact cylindrical device that uses a radial flow pattern towards the center of the device to mobilize the foundation material and carrying it away. In this study the previously calibrated ESTD is used as a reference to characterize the performance of the LabISTD, and therefore establish a calibration procedure that enables the Lab-ISTD to produce necessary parameters for better bridge scour evaluation and foundation design.
\end{abstract}

\section{INTRODCTIONS}

In order to promote bridge safety under flood conditions, the U. S. Federal Highway Administration (FHWA) has been developing more reliable bridge scour evaluation methods that take into account bridge site characteristics, including site specific flow conditions and stream bed material properties. The most direct methods for the characterization of stream bed erodibility is the use of erosion testing devices utilizing flow that simulates stream flow conditions during flood. The FHWA Hydraulics Research Program, supported by Genex Systems researchers, is currently developing two such devices: the Ex-situ Scour Testing Device (ESTD, Shan et al. 2015) and the In-situ Scour Testing Device (ISTD, Zinner et al. 2016). Besides these two devices, other laboratory and field scour testing devices have been designed to assist the development of the testing methodology. A laboratory version of the ISTD (Lab-ISTD) was designed for this purpose. The LabISTD produced a very similar flow pattern as that of the ISTD. It offers detailed instrumentation and observation of flow in the erosion chamber so that the design can be optimized and results calibrated for accurate representation of soil erodibility. The difference between the log-law flow in the ESTD, which mimics the open channel flow, and the radial flow in the ISTD and Lab-ISTD makes the theories that correlate the flow rate with shear stress in open channel not directly applicable to the ISTD and LabISTD. It is necessary to establish a new relationship that predicts the erosion capability of the flow in the ISTD/Lab-ISTD based on a few key parameters in reference to open channel flow. The main parameters include the gap between the erosion head and the underlying foundation material, and the flow rate through the erosion head. This paper presents the development of the calibration process that correlates the erosion testing results of the Lab-ISTD to the erosion at bridge sites during floods. The calibration utilizes a comparison of the Lab-ISTD to the ESTD, for which we have more detailed measurement regarding the flow conditions experienced during tests. With these measurements available the tests can be better correlated to the stream flow conditions.

\subsection{Existing devices}

Many laboratory and field soil testing devices have been developed in the past several decades. These devices include:

- Circular Couette flow erosion device (CCFED, Moore and Masch 1961)

- Jet erosion test (JET, Hanson and Cook 2004)

- Erosion function apparatus (EFA, Briaud et al. 2001) 
- Hole erosion test (HET, Wan and Fell 2004)

- Sediment erosion rate flume (SERF, Sheppard and Bloomquist 2005)

- Virginia Institute of Marine Science (VIMS) sea carousel (Maa et al. 1993)

- In-situ erosion flume (ISEF) (Houwing \& van Rijn, 1998)

- Ex situ scour testing device (ESTD, Shan et al. 2010, 2015)

- In situ scour testing device (ISTD, Zinner et al. 2016).

These devices simulate different flow conditions including Couette flow, conduit flow, seepage and open channel flow. Each of these devices provides unique superiority in studying soil erosion in either laboratory or field. However, comparison among these devices is very challenging, which greatly limits the application of these devices.

\subsection{Ex situ Scour Testing Device (ESTD)}

FHWA (Shan et al. 2010, 2015) developed the ESTD to study the erodibility of cohesive soils. The ESTD is a laboratory device with well-controlled flow conditions and shear stress measurement. It uses a moving belt and a centrifugal pump to reproduce open channel flow conditions in its test channel. The channel is $58 \mathrm{~cm}$ long, $12 \mathrm{~cm}$ wide and 2 $\mathrm{cm}$ deep. The channel bed is roughened by mounting sandpapers from p-grades 80 to 320 to simulate different roughness. The ESTD is capable of directly measuring the bed shear stress acting on the testing soil during an erosion test. Through Particle Imaging Velocimetry (PIV), it is validated that the flow in ESTD simulates the near-bed layer of the open channel flow during floods.

At the beginning of an erosion test, the soil surface was flush with the channel bottom. During the erosion process, the soil position was automatically lifted or lowered to keep the constant bed shear stress (the form drag because of the protrusion is minimum and negligible). Erosion rates of artificial Illite clay at varied bed shear stress were collected. Critical shear stress was formulated with water content, percentage of finer material, plasticity index and unconfined compressive strength. Shan et al. (Shan et al. 2015) also formulated the erosion function (the relationship between erosion rates and shear stresses) with critical shear stress and other soil properties.

\subsection{Laboratory In situ Scour Testing Device (Lab- ISTD)}

The ISTD (Zinner et al. 2016) is a field device that is compatible with conventional geotechnical subsurface exploration equipment and can test soil erodibility where a bridge is founded.
To maintain portability and robustness, the ISTD has evolved into a compact cylindrical device that fits into a normal hollow stem auger. The experimental model features a 3D printed erosion head that is $82.6 \mathrm{~mm}$ in diameter, encased in a steel sampler casing (88.9 $\mathrm{mm}$ in diameter). The geometry of the erosion head is optimized through Computational Fluid Dynamics (CFD) simulations. At the tip of the erosion head, water flows radially towards the center of the device, mobilizing the foundation material and carrying it away. This horizontal radial flow effectively produces high shear stress similar to that of open channel flow during a flood.

A laboratory version of the ISTD was designed to facilitate the ISTD development (Figure 1). Unlike the erosion head cutting into the soil in the ISTD, the Lab-ISTD uses a piston to push soil up while keeping the erosion head still. The dimension of the LabISTD was also different from the ISTD. The main components of the Lab-ISTD include the erosion head, the soil tube and the piston. The system can have a maximum flow rate of $51 / \mathrm{s}$, as measured by a flow meter.

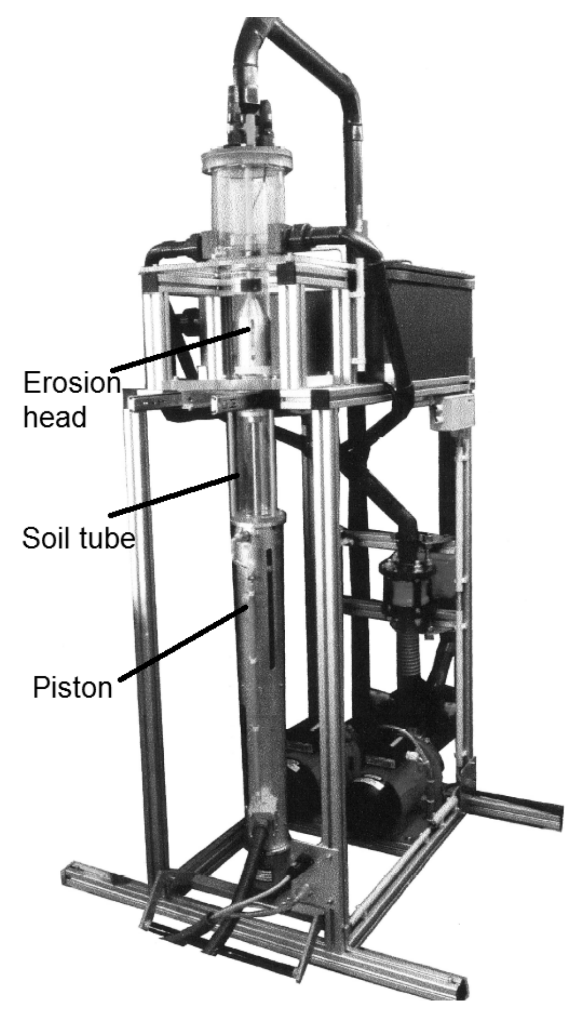

Figure 1. Photo of the Lab-ISTD.

The erosion head used for preliminary tests in Lab-ISTD has a shape illustrated in Figure 2. The casing has identical dimensions as that of the soil tube. They both have an outer diameter of $76.2 \mathrm{~mm}$ and an inner diameter of $73 \mathrm{~mm}$. This enables the test of conventional 3" Shelby tube field soil samples. The erosion head has a diameter of $67 \mathrm{~mm}$. Water flows down through the gap between the casing and the erosion head; turns horizontally under the 
erosion head; then flows upward vertically through the center of the erosion head. Inside the erosion head, an ultrasonic sensor is embedded to measure the gap between the erosion head and the underneath soil surface. The ultrasonic sensor has a dimension of $8 \mathrm{~mm}$, and is $25 \mathrm{~mm}$ away from the center of the erosion head.

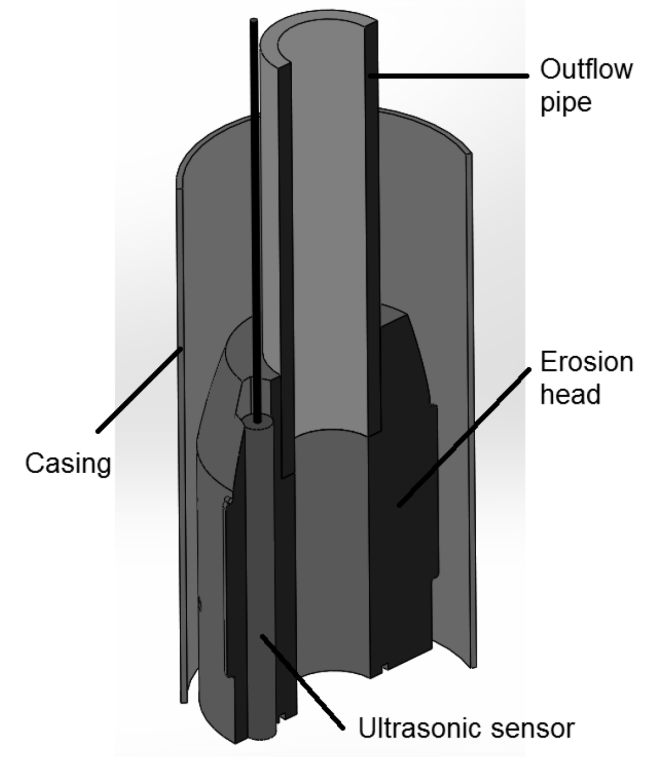

Figure 2. Sketch of the erosion head.

The Lab-ISTD is capable of testing lab-prepared and field soils. Lab-prepared soils can be inserted in a $30-\mathrm{cm}$ transparent polycarbonate soil tube. The transparent tube enables the observation of the erosion process. This may facilitate the improvement of the erosion head. For field soils, a $30-\mathrm{cm}$ section of Shelby tube samples can be directly mounted onto the Lab-ISTD and tested. This minimizes the disturbance to the field soils when it is transferred into a testing apparatus.

As the erosion proceeds, the gap between the erosion head and the soil surface increases. In order to keep a constant gap, soil needs to be pushed up by the piston. The piston does so based on the difference between the real gap and the desired gap. The real gap is measured by the ultrasonic sensor. The ultrasonic sensor measures the time difference between sending the initial signal and receiving the reflected signal for calculation of the gap. The sensor is both an emitter and a receiver. It sends out a pulse of 2 $\mathrm{MHz}$ ultrasonic waves in water every $20 \mathrm{~ms}$. Because the sensor has an aperture of $8 \mathrm{~mm}$ and therefore a signal cone with a considerable size, the reflected signal consists of backscattering front the soil surface of different distances, which makes it difficult to determine the exact travel time of the signal from the true target. To solve this problem, the reflected signal is captured using a high speed data acquisition card with a sampling frequency of $50 \mathrm{MHz}$. By conducting cross correlation between the emitted and received signals, the travel time of the signal can be determined by the "hotspot" in the crosscorrelation between the emitted and received signals. Knowing the wave speed, the gap between the erosion head and soil surface can be calculated. Here, we assume the soil surface would not change dramatically within $20 \mathrm{~ms}$ due to erosion.

\subsection{Calibration of the flow conditions}

Table 1 outlines the difference between the ESTD, ISTD and Lab-ISTD in terms of flow condition, erosion process and tested soil size.

Table 1. Comparison among the three devices

\begin{tabular}{|c|c|c|c|}
\hline & \multicolumn{3}{|c|}{ Device } \\
\hline & ESTD & Lab-ISTD & ISTD \\
\hline Flow condition & $\begin{array}{l}\text { Open channel } \\
\text { flow }\end{array}$ & Radial flow & Radial flow \\
\hline Flow orientation & Horizontal & Horizontal & Horizontal \\
\hline Erosion control & $\begin{array}{l}\text { Constant shear } \\
\text { stress }\end{array}$ & $\begin{array}{l}\text { Constant gap \& } \\
\text { flow rate }\end{array}$ & $\begin{array}{l}\text { Constant gap \& } \\
\text { flow rate }\end{array}$ \\
\hline Erosion process & Soil pushed up & Soil pushed up & $\begin{array}{l}\text { Erosion head cut } \\
\text { in soil }\end{array}$ \\
\hline Shear stress & $\begin{array}{l}\text { Directly meas- } \\
\text { ured }\end{array}$ & $\begin{array}{l}\text { Calibrated to } \\
\text { ESTD }\end{array}$ & $\mathrm{N} / \mathrm{A}$ \\
\hline Tested soil size & $\begin{array}{l}\text { Cylinder: } 63 \mathrm{~mm} \\
\text { diameter } \& \\
20 \mathrm{~mm} \text { height }\end{array}$ & $\begin{array}{l}\text { Cylinder: } 73 \mathrm{~mm} \\
\text { diameter \& } \\
\text { 300mm height }\end{array}$ & $\begin{array}{l}\text { Cylinder: } 89 \mathrm{~mm} \\
\text { diameter \& infi- } \\
\text { nite height }\end{array}$ \\
\hline
\end{tabular}

The ESTD reproduces the open channel flow in its test channel, while the Lab-ISTD and field ISTD have a radial flow condition in the casing. The difference between the open channel flow and the radial flow makes the theories that correlate the shear stress with velocity (flow rate) in open channel not directly applicable to the Lab-ISTD. Thus, it is necessary to establish a new relationship that correlates the erosion capability of the flow in Lab-ISTD to that of the open channel flow. The main parameters include the gap between the erosion head and the soil surface, and the flow rate through the erosion head.

In this study the previously calibrated ESTD is used as a reference of open channel flow to characterize the performance of the Lab-ISTD, and therefore establish the aforementioned relationship as a calibration procedure that enables the field ISTD to produce necessary parameters for better bridge scour evaluation and foundation design.

\section{CALIBRATION BETWEEN ESTD AND LAB- ISTD}

Calibration between the ESTD and the Lab-ISTD is done by finding equivalent flow conditions in these two devices. The flow conditions in both devices are assumed equivalent if the same erosion rate of identical soil samples is obtained in both devices under these two flow conditions. 


\subsection{Soils for calibration}

Shan et al. (2015) produced man-made cohesive soils by mixing dry powder of clay, silt and sands in a pugger mixer. Unlike conventional soil preparation by the method outlined in standard compaction test, the pugger mixer can vacuum the mixture during the preparation. This dramatically improves the saturation degree of the man-made cohesive soils from around $75 \%$ (compaction method) to almost fully saturated (pugger mixer). The almost fully saturated cohesive soil is then free of slaking unlike the soils prepared by the compaction method. Slaking is a completely different mechanism for soil loss than the erosion process, therefore slaking should be avoided in erosion test (Shan et al. 2015).

17 different cohesive soils were prepared using the pugger mixer and tested in the ESTD. The critical shear stress and erosion rates of those soils had been obtained. With this information available, the same soil can be prepared and tested in the Lab-ISTD. The erosion rates will then be reproduced in the LabISTD on the same soil samples. The flow rates in the Lab-ISTD that reproduce the erosion rates from ESTD would be correlated to the shear stress measured in ESTD during the erosion test.

Two soils were prepared to calibrate the two devices. They are soil samples 5W215 and 6W200, i.e. soil \#5 with a water content of $21.5 \%$ and soil \#6 with a water content of $20.0 \%$. Table 2 gives the classification and composition of the two soils.

Table 2. Classification and composition of soils

\begin{tabular}{|c|c|c|c|c|c|c|}
\hline \multirow{2}{*}{ Soil } & \multirow{2}{*}{$\begin{array}{l}\text { Soil } \\
\text { Type }\end{array}$} & \multicolumn{3}{|c|}{ Source Mix (\%) } & \multirow{2}{*}{$\begin{array}{l}\text { Specific } \\
\text { Gravity }\end{array}$} & \multirow{2}{*}{$\begin{array}{c}\text { Plastic } \\
\text { Limit } \\
(\%)\end{array}$} \\
\hline & & Red Art & Silt & Sands & & \\
\hline $5 \mathrm{~W} 215$ & CL & 40 & 40 & 20 & 2.71 & 17.7 \\
\hline $6 \mathrm{~W} 200$ & $\mathrm{CL}$ & 40 & 30 & 30 & 2.72 & 16.6 \\
\hline \multirow[b]{2}{*}{ Soil } & Liquid & \multicolumn{4}{|c|}{ Fraction (\%) } & Plasticity \\
\hline & $\begin{array}{c}\text { Limit } \\
(\%)\end{array}$ & $<2 \mu \mathrm{m}$ & $<50 \mu \mathrm{m}$ & $<75 \mu \mathrm{m}$ & $<425 \mu \mathrm{m}$ & $\begin{array}{c}\text { Index } \\
(\%)\end{array}$ \\
\hline $5 \mathrm{~W} 215$ & 26.4 & 13.5 & 78.9 & 80.3 & 88.6 & 8.7 \\
\hline $6 \mathrm{~W} 200$ & 25.5 & 12.9 & 69.2 & 70.4 & 82.9 & 8.9 \\
\hline
\end{tabular}

The 5W215 soil has a wet bulk density of 2085 $\mathrm{kg} / \mathrm{m}^{3}$, dry bulk density of $1717 \mathrm{~kg} / \mathrm{m}^{3}$, void ratio of $57.8 \%$, saturation degree of $100.4 \%$, and unconfined compressive strength of $144.1 \mathrm{kPa}$. The $6 \mathrm{~W} 200$ soil has a wet bulk density of $2078 \mathrm{~kg} / \mathrm{m}^{3}$, dry bulk density of $1733 \mathrm{~kg} / \mathrm{m}^{3}$, void ratio of $57.0 \%$, saturation degree of $95.1 \%$, and unconfined compressive strength of $78.3 \mathrm{kPa}$.

\subsection{Experiment procedures}

The two soils were prepared by mixing specified percentage of soil components in the pugger mixer. After a uniform texture was achieved, the mixture was stored in a sealed container for at least 16 hours.
Then the mixture was remixed in the pugger. At the end of the mixing, the mixture was vacuumed. Then it was extruded into the $30-\mathrm{cm}$ soil tube of the LabISTD.

The first several centimeters of the soil in the tube was discarded due to cracks developed during the filling process. Thus, the initial soil surface was flush with the top tip of the soil tube. The soil tube was then mounted onto the piston, and fastened to the Lab-ISTD. This left a gap about $25 \mathrm{~mm}$ between the erosion head and the soil surface.

A program was composed on LabVIEW platform to control the experiment. It regulated the pump to supply water to the system. The flow rate measured by the flow meter was shown in the program. A constant gap size between the erosion head and soil surface was given to the program to automatically control the piston movement to maintain the gap size. The program also recorded the flow rate, piston displacement, and gap between the erosion head and soil surface along with the time. Erosion rate was calculated in the post processing of the recorded data. In the experiment, the gap was set to be $30 \mathrm{~mm}$. At any time, if the gap is larger than $30 \mathrm{~mm}$, the piston would push the soil up with a distance of the exact gap difference.

\section{RESULTS}

\subsection{Erosion rates of soils}

Figure 3 illustrates the erosion curve of soil 5W215 at several arbitrary flow rates recorded in the LabISTD.

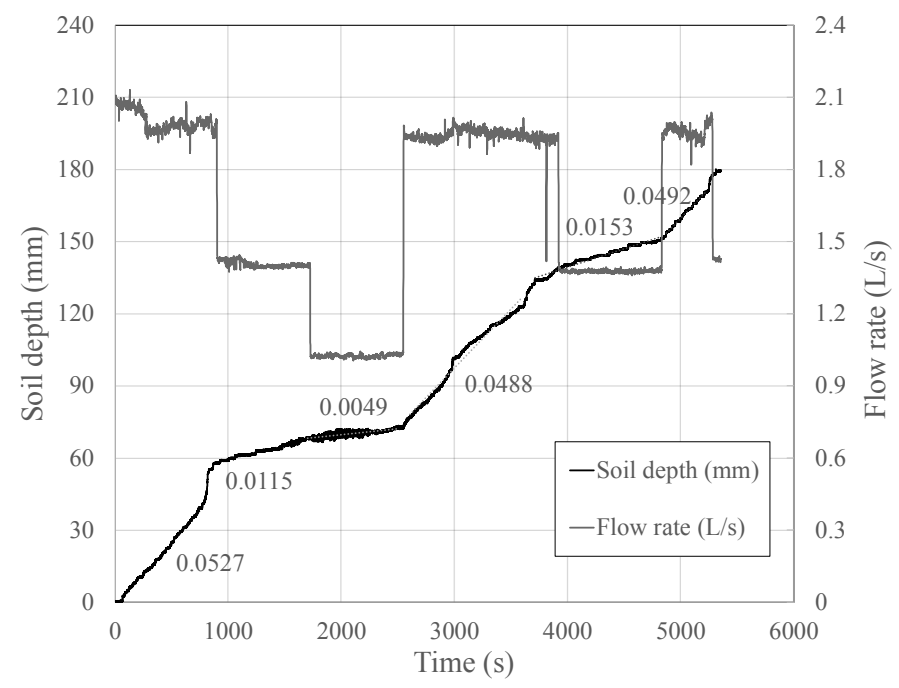

Figure 3. An erosion curve for soil 5W215.

As can be seen from figure 3 , three flow rates were used in the test: $1,1.4$ and $2.0 \mathrm{l} / \mathrm{s}$. Both 1.4 and $2.0 \mathrm{l} / \mathrm{s}$ flow rates were repeated in order to validate the repeatability of the experiment. For each flow rate, the depth of the soil was plotted with respect to the time and fitted with a linear function. The slope from the fitted line was the erosion rate. For all three 
$2.01 / \mathrm{s}$ flow rates, the erosion rates were 0.0527 , 0.0488 and $0.0492 \mathrm{~mm} / \mathrm{s}$. The average erosion rate was $0.0502 \mathrm{~mm} / \mathrm{s}$. The standard deviation of the three erosion rates was 0.002 , and the coefficient of variation $(\mathrm{COV})$ was 0.04 . These indicate a good repeatability of the test. The two repeated flow rates of $1.4 \mathrm{l} / \mathrm{s}$ also prove the good repeatability of the test.

\subsection{Calibration of flow conditions}

A soil erodibility study in ESTD (Shan et al. 2015) gave the erosion function of the two soils in a form:

$e=C_{1}\left(\tau-\tau_{c}\right)^{1.8}$

where $e=$ soil erosion rate with a unit of $\mathrm{mm} / \mathrm{hr} ; C_{l}$ $=$ multiplier coefficient; $\tau=$ eroding shear stress from the flow; and $\tau_{c}=$ critical shear stress of a soil. $C_{1}$ and $\tau_{c}$ were also given. For soil $5 \mathrm{~W} 215, C_{1}=$ $0.069, \tau_{c}=6.75 \mathrm{~Pa}$; for soil $6 \mathrm{~W} 200, C_{1}=0.124, \tau_{c}=$ 4.84 Pa.

Applying equation 1 to measured erosion rate from table 3 , the corresponding shear stress can be calculated, and are given in table 3 . As indicated before, the calculated shear stress is equivalent shear stress in the ESTD.

Table 3. Erosion rates of two soils with a controlled $30 \mathrm{~mm}$ gap.

\begin{tabular}{cccccc}
\hline \multicolumn{3}{r}{ Soil 6W200 } & \multicolumn{3}{c}{ Soil 5W215 } \\
\hline $\mathrm{Q}(\mathrm{l} / \mathrm{s})$ & $\mathrm{e}(\mathrm{mm} / \mathrm{s})$ & $\tau(\mathrm{Pa})$ & $\mathrm{Q}(\mathrm{l} / \mathrm{s})$ & $\mathrm{e}(\mathrm{mm} / \mathrm{s})$ & $\tau(\mathrm{Pa})$ \\
\hline 1 & 0.0018 & 13.8 & 1 & 0.0049 & 28.5 \\
1.5 & 0.0092 & 27.1 & 1.4 & 0.0153 & 47.7 \\
2 & 0.06 & 68.0 & 1.4 & 0.0115 & 41.7 \\
& & & 2 & 0.0527 & 88.2 \\
& & & 2 & 0.0488 & 84.8 \\
& & & 2 & 0.0492 & 85.1 \\
& & & 2.2 & 0.03 & 66.3 \\
& & & 2.8 & 0.1258 & 138.8 \\
\hline
\end{tabular}

The equivalent shear stress was plotted against the flow rate in the Lab-ISTD (figure 4).

As can be seen from figure 4 , the relationship between the equivalent shear stress and the flow rate in the Lab-ISTD can be approximated by a power law function. The power function reads:

$\tau_{e}=20 Q^{1.87}$

where $\tau_{e}=$ equivalent shear stress in the ESTD; and $Q=$ flow rate in the Lab-ISTD.

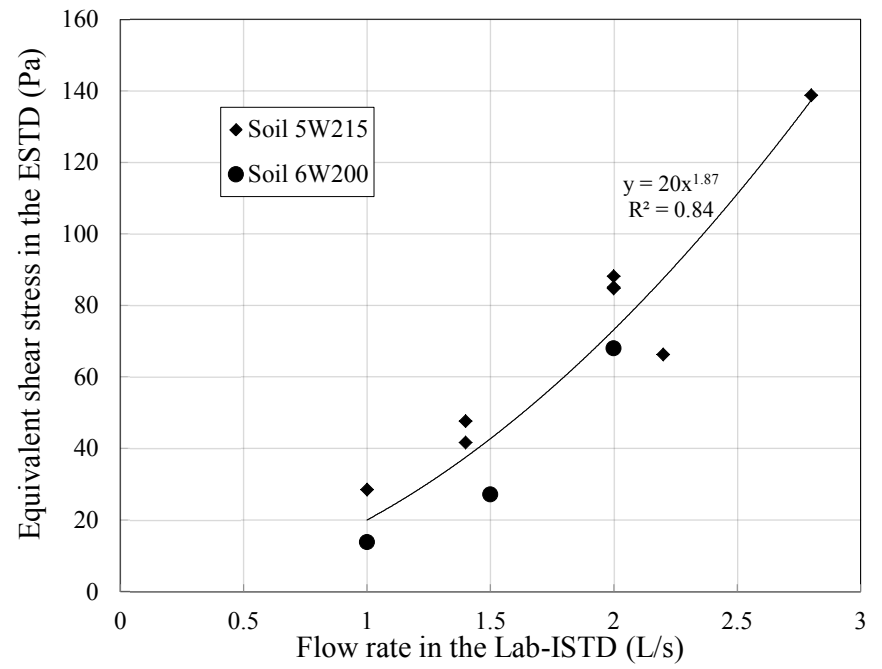

Figure 4. Relationship between the equivalent shear stress and the flow rate in the Lab-ISTD.

Equation 2 represents the calibration function between the ESTD and the Lab-ISTD. Please note that equation 2 was for a constant $30 \mathrm{~mm}$ gap between the soil surface and the erosion head. If the gap size and the shape of erosion head change, the calibration function will also change.

The calibrated Lab-ISTD represents an equivalent testing platform of ISTD, but with extended high flow capacity. The same calibration procedure can be applied to the field ISTD to correlate the field data with validated lab results.

\section{DISCUSSION}

The ESTD reproduces the open channel flow by generating log-law velocity profiles in its test channel. The bed shear stress was directly measured by a shear sensor, and double checked with the velocity profile from PIV measurements. The Lab-ISTD has a radial flow condition. Meanwhile, the flow in the Lab-ISTD may have a greater turbulent intensity depending on the shape of the erosion head. These factors prohibit a direct measurement of the velocity profile and the bed shear stress in the Lab-ISTD. By having the same erosion rate in the Lab-ISTD and the ESTD, the equivalent shear stress as a function of the flow condition in the Lab-ISTD can be obtained. With the calibration function known, a flow condition in the Lab-ISTD can be correlated to a known shear stress in the ESTD.

Erosion rate of tested soil in the Lab-ISTD depends on the magnitude of the flow rate, the gap between the erosion head and soil surface, the shape of the erosion head and soil properties. Figure 5 shows the next generation erosion head. The duct entering at the center of the top of the device (darker shade) connects the water supply pipelines, and the Yshaped duct having two opening at the top and one opening at the bottom (lighter shades) allows the water to exit the erosion chamber carrying the eroded 
material away. The inflow is divided into 4 branches of water supply into the erosion chamber. Compared to the erosion head in figure 2 , the changes made were purported to increase the system performance based on the experience gained during the lab/field testing of ISTD and from CFD simulations. The erosion power produced by the new erosion head might be somewhat different from that of the current LabISTD. However, by assuming the same erosion rate is generated by equivalent flow condition, the new erosion head can be calibrated using the same procedure described above.

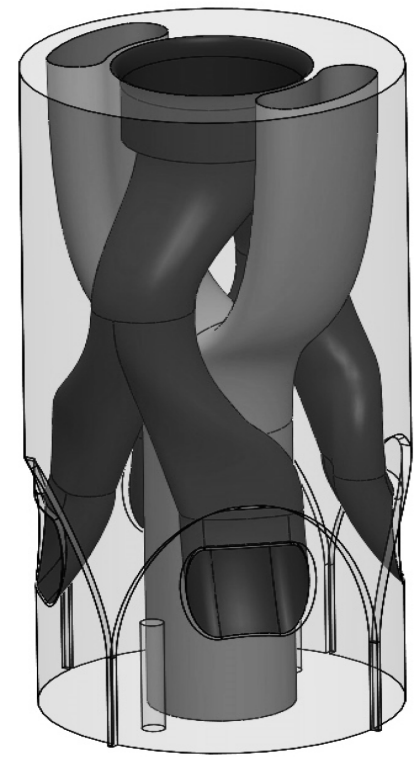

Figure 5. Erosion head of next generation in the Lab-ISTD.

\section{CONCLUSIONS}

Two scour testing devices were developed by the FHWA Hydraulics Research Program: the ESTD and the Lab-ISTD. The ESTD reproduced open channel flow and directly measured the bed shear stress, while the Lab-ISTD has flow conditions somewhat different from that of an open channel. By obtaining a same erosion rate of identical soil in both devices, the flow conditions in both devices are deemed as equivalent in terms of erosion power. Equation 2 gives the calibration function of the equivalent shear stress in the ESTD with the flow rate in the Lab-ISTD for a constant $30 \mathrm{~mm}$ gap between the erosion head and the soil surface. With a series of curves in the format of equation 2 derived from a calibration through various range of flow rates and gap sizes, the equivalent shear stress can be obtained for all settings of the Lab-ISTD. This enables the Lab-ISTD to accomplish robust erodibility testing for field soils.

\section{REFERENCES}

Briaud, J. L., Ting, F. C. K., Chen, H. C., Cao, Y., Han, S. W. \& Kwak, K. W. 2001. Erosion function apparatus for scour rate predictions. J. Geotech. Geoenviron. Eng., 127 (2): 105-113.

Hanson, G. J., \& Cook, K. R. 2004. Apparatus, test procedures and analytical methods to measure soil erodibility in situ. Applied Engineering in Agriculture, 20(4): 455-462.

Houwing, E. J. \& van Rijn, L. C. 1998. In situ erosion flume (ISEF): determination of bed-shear stress and erosion of a kaolinite bed. Journal of Sea Research, 39(3-4): 243-253.

Maa, J. P.-Y., Wright, L. D., Lee, C.-H. \& Shannon, T. W. 1993. VIMS sea carousel: A field instrument for studying sediment transport. Marine Geology, 115(3-4): 271-287.

Moore W. L. \& Masch F. D. 1961. Experiment on the scour resistance of cohesive sediments. Presentation before the Symposium on Sedimentation, American Geophysical Union, Washington D. C.

Shan, H. 2010. Experimental Study on Incipient motion of Noncohesive and Cohesive Sediments, Ph.D. Dissertation, University of Nebraska-Lincoln, Lincoln, NE.

Shan, H., Shen, J., Kilgore, R. \& Kerenyi, K. 2015. Scour in cohesive soils. FHWA Report: FHWA-HRT-15-033, Washington DC.

Sheppard, D. M. \& Bloomquist, D. 2005. Water erosion of Florida rock materials. FDOT BC354 RPWO \#12, Tallahassee, Florida.

Wan, C.F. \& Fell, R. 2004. Investigation of rate of erosion of soils in embankment dams. J. Geotech. Geoenviron. Eng., 130(4): 373-380.

Zinner, M., Meyer, T., Shan, H., Shen, J., Bergendahl, B. \& Kerenyi, K. 2016. A field erodibility testing device for scour evaluation of bridges. Proceedings of the ICSE-8, London, UK. 